\title{
Single System Ectopic Congenital Giant Megaureter Associated with Ipsilateral Multicystic Dysplastic Kidney
}

\author{
Santosh Kumar Mahalik*, Bikasha Bihary Tripathy, Akash Bihari Pati, Manoj Kumar Mohanty \\ Department of Pediatric Surgery, All India Institute of Medical Sciences, Bhubaneswar, Sijua, Patrapada, Bhubaneswar (Odisha)
}

\begin{abstract}
Congenital anomalies of the kidney and urinary tract (CAKUT) is a disease spectrum of a wide range of structural and functional anomalies. In this report, we have presented a rare case of CAKUT displaying the wide spectrum of renal and urinary tract anomalies with an unusual association like single system ectopic giant megaureter with the ipsilateral multicystic dysplastic kidney.
\end{abstract}

\section{Keywords: CAKUT; Congenital giant megaureter; Single system ectopic ureter; MCDK}

Correspondence*: Santosh Kumar Mahalik, Department of Pediatric Surgery, All India Institute of Medical Sciences, Bhubaneswar, Sijua, Patrapada, Bhubaneswar (Odisha)

E-mail: dr.santosh25@gmail.com

(c) 2018, Mahalik et al

Submitted: 24-01-2018

Accepted: 17-04-2018

Conflict of Interest: None

Source of Support: Nil

This is an open-access article distributed under the terms of the Creative Commons Attribution License, which permits unrestricted use, distribution, and reproduction in any medium provided the original work is properly cited.

\section{INTRODUCTION}

Congenital anomalies of kidney and urinary tract (CAKUT) is a disease spectrum covering wide range of renal system structural and functional malformations that occur at the level of Kidney (hypoplasia and dysplasia), collecting system (hydronephrosis and megaureter), bladder (ureterocele and vesicoureteral reflux) or urethra (posterior urethral valve).[1] We are reporting a rare case of CAKUT with unusual combination of single system ectopic congenital giant megaureter with ipsilateral multicystic kidney disease. Only one such reported article is available till date displaying the wide spectrum of CAKUT.[2]

\section{CASE REPORT}

An eight-year-old female child presented with complaints of dribbling of urine since birth despite having normal voluntary voiding habits. She had history of repeated urinary tract infections for which she was treat- ed with different antibiotics. On checking the previous health records, antenatal ultrasonography (USG) done at 23 weeks of intrauterine life revealed moderate pelvicalyectasis of right fetal kidney with grossly dilated \& tortuous right fetal ureter crossing midline to the left side and then returning to right side to join the urinary bladder. Left fetal kidney, ureter and bladder were normal and amniotic fluid was adequate. The child had normal urethral and vaginal openings and pooling of urine in vagina was noted on clinical examination. Her renal function tests were within normal limit. A repeat USG revealed contracted right kidney $(61 \times 34 \mathrm{~mm})$ with multiple cysts in renal parenchyma, and the kidney was hypertrophied $(93 \times 46 \mathrm{~mm})$. A fluid-filled tubular structure of size $73 \times 29 \mathrm{~mm}$ was noted along right posterolateral aspect of urinary bladder (? dilated ureter). Further investigation with CT Urogram showed small contracted right kidney with dysplastic renal parenchyma \& presence of multiple small cortical cysts. There was negligible contrast excretion into dilated 
proximal right ureter in delayed films. Right ureter was dilated on its entire course with more pronounced dilatation of distal ureter $(3.2 \mathrm{~cm})$ and ectopic extravesical insertion of distal ureter into cervicovaginal canal [Figure 1]. DTPA scan confirmed negligible function of right kidney. Preoperative cystogenitoscopy confirmed right hemi-trigone and non-localization of right ureteric orifice. With all investigation the final diagnosis was single system ectopic congenital giant megaureter with ipsilateral multicystic dysplastic kidney (MCDK) for which laparoscopic nephroureterectomy was performed [Figure 2]. The child is asymptomatic during follow up.

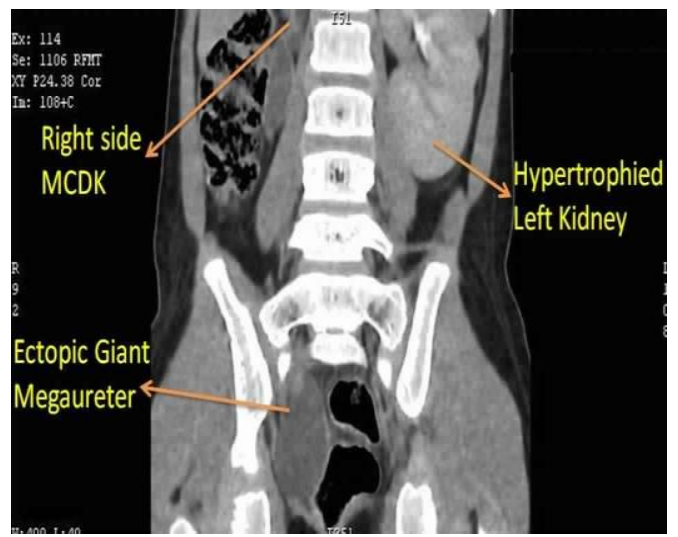

Figure 1: Contrast enhanced CT scan showing right side ectopic giant megaureter with ipsilateral MCDK.

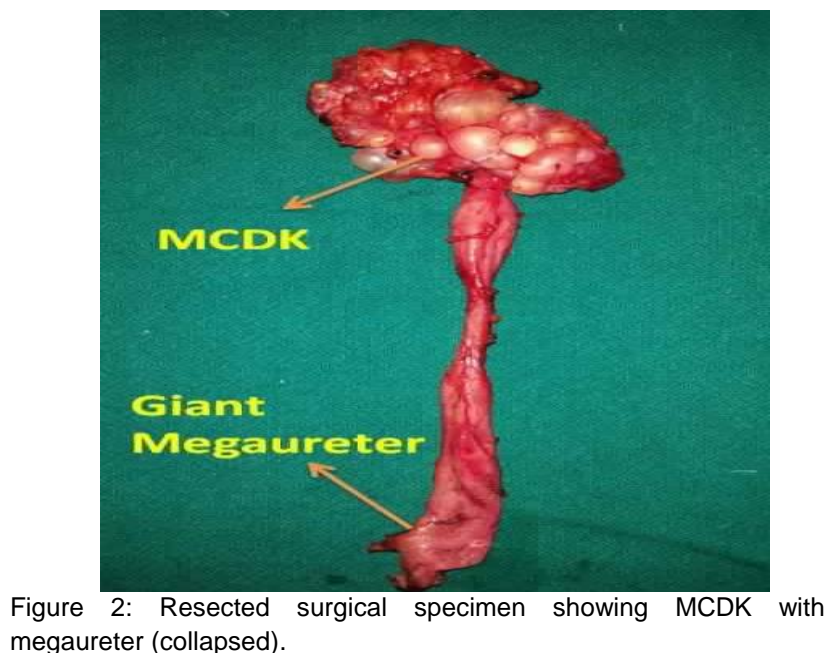

\section{DISCUSSION}

Congenital giant megaureter (CGM) is an extremely rare condition, which is defined as "ureter whose lumen is congenitally, focally or segmentally dilated to more than 10 times of the normal diameter, in presence of normal bladder volume \& function".[3] The upper limit of normal size for non-obstructed ureter on unenhanced helical CT scan is $3 \mathrm{~mm}$.[4] Hence, ureteral dilatation beyond $3 \mathrm{~cm}$ is designated as giant megaureter. In our case, the child had ureter size of maximum $3.2 \mathrm{~cm}$ qualifying as a giant megaureter. In the largest series of 21 cases published by Huang et al, 12 patients had duplex collecting system on affected side (most common association). The other described associated congenital anomalies are ureterocele, ectopic ureter, crossed ectopic ureter, ureteral atresia, supernumerary kidneys etc. $[3,5]$

Multicystic dysplastic kidney (MCDK) is invariably associated with ipsilateral atretic ureter and most of these undergo involution within first 5 years of life. However, it can rarely occur in conjunction with ureteral dilatation and a ureterocele in both instances, the underlying mechanism is believed to be an obstructive insult to the developing metanephric mesenchyme at an early stage in gestation. The most common association of MCDK is contralateral vesico-uretric reflux (VUR) being 1843\%.[6] Apart from this pelvi-ureteric junction obstruction (PUJO) and vesico-ureteric junction obstruction (VUJO) has also been reported in the contralateral kidney. Ectopic ureters are rarely reported in association of MCDK.[7]

More than $80 \%$ of ectopic ureter generally arises from upper pole of completely duplicated system. An ectopic ureter draining a single system renal unit is a rare anomaly, especially in females and it is rare to find association of unilateral single system ectopic ureter draining a dysplastic or hypoplastic kidney.[7] Our case is unique in the way that the girl has a combination of rare congenital renal and urinary tract anomalies like single system ectopic giant megaureter associated with ipsilateral MCDK. Ucar et al in 2014, presented a similar case of unilateral megaloureter, MCDK and ectopic ureter in a female neonate and ours is the second such case where all these extremely rare combination is seen. [2] The above described anomalies come under a disease spectrum called congenital anomalies of kidney and urinary tract (CAKUT).

CAKUT is a family of disease with a diverse anatomical spectrum including kidney anomalies eg. multicystic dysplastic kidney, pelvic-ureteric junction obstruction, vesico-ureteric reflux, megaureter etc. These abnormalities are often present simultaneously and take the familial pattern with incomplete \& variable penetrance often producing the different anatomical pattern. Hence, it is speculated that these anomalies may share a common pathogenic mechanism and genetic cause.[1] 
According to Mackie \& Stephens popular hypothesis, when ureteral budding from the Wolffian duct occurs at an ectopic site, the final site of the ureteric orifice will be ectopic as well, and this ectopic budding has the potential to produce anomalous kidney parenchyma, which becomes the precursor for the hypo-plastic and or dysplastic kidney. This explains ectopic ureter along with MCDK in the present case. Therefore, the anomalies of multiple tissues constituting CAKUT can be derived from single abnormal embryonic event i.e. ectopia in initial ureteral budding.[2]

To conclude, congenital anomaly of kidney and urinary tract (CAKUT) is a condition with wide spectrum anomalies. Single system ectopic congenital giant megaureter with ipsilateral MCDK is rare association which signifies the diversity \& spectrum of CAKUT and needs extensive investigation and proper management.

\section{Consent Statement}

Authors declared that they have taken informed written consent, for publication of this report along with clinical photographs/material, from the legal guardian of the patient with an understanding that every effort will be made to conceal the identity of the patient however it cannot be guaranteed.

\section{Author's Contributions}

All authors contributed equally in concept, design, literature review, drafting the manuscript, and approval of the final manuscript.

\section{REFERENCES}

1. Kuwayama F, Miyazaki Y, Ichikawa I. Embryogenesis of the congenital anomalies of the kidney and the urinary tract. Nephrol Dial Transplant. 2002; 17:45-7.

2. Uçar M, Oksay T. A case of unilateral megaloureter, multicystic renal dysplasia and ectopic ureter in a female neonate. Eur Urol. 2014; 13:e1490.

3. Ramaswamy R, Ravi G, Baz AR, Mukattash IG, Saeed S. Congenital giant megaureter associated with ipsilateral multicystic dysplastic kidney in newborn. Pediatr Urol Case Rep. 2016; 3:1-6.

4. Zelenko N, Coll D, Rosenfeld AT, Smith RC. Normal ureter size on unenhanced helical CT. AJR AM J Roentgenol. 2004; 182: 1039-41.

5. Huang CJ. Congenital giant megaureter. J Pediatr Surg. 1987; 22:235-9.

6. Glassberg KL, Hyun G. Renal Agenesis, Dysplasia, and Cystic Disease. In: Coran AG, editor-in-chief. Pediatric Surgery. 7th edn. USA: Elsevier, Saunders; 2012. 13951403.

7. Borer JG, Bauer SB, Peters CA, Diamond DA, Decter DA, Shapiro E. A single-system ectopic ureter draining an ectopic dysplastic Kidney: delayed diagnosis in the young female with continuous urinary incontinence. $\mathrm{Br} \mathrm{J}$ Urol. 1998; 81:474-8. 